\title{
RapidEye ve PlanetScope uydu bantları ile pamuk bitkisi yaprak azot içeriğinin belirlenmesi
}

Determination of nitrogen content of cotton plant leaves from RapidEye and PlanetScope satellite data

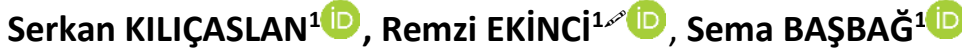 \\ ${ }^{1}$ Dicle University, Faculty of Agriculture, Department of Field Crops, Diyarbakir, Turkey.
}

MAKALE BILGISI / ARTICLE INFO

Makale tarihçesi / Article history:

DOI: $10.37908 /$ mkutbd.654258

Geliş tarihi /Received:02.12.2019

Kabul tarihi/Accepted:30.04.2020

\section{Keywords:}

Cotton, nitrogen, satellite images, remote sensing, RapidEye, PlanetScope.

Corresponding author: Remzi EKINCI

$\triangle$ : remzi.ekinci@dicle.edu.tr
ÖZET / A B STR A C T

\begin{abstract}
Aims: The aim of this study was to determine the changes in nitrogen contents of cotton plant leaves by using satellite images, to estimate nitrogen status in the plant leaves with the help of satellite images, and to determine nitrogen fertilizer requirements in large cotton production areas by using satellite images in the future to make nitrogen application recommendations.

Methods and Results: The experiment was carried out in randomized plot design with three replications in six different locations under Mardin province ecological conditions in Turkey. Data from four bands of PlanetScope and five bands of RapidEye satellites were used in the study. The correlation between leaf nitrogen content and reflectance of satellite bands was determined and regression (leaf nitrogen content-reflectance) and reverse regression (reflectance-leaf nitrogen content) analyses were performed. Significant correlation were found between leaf nitrogen content and RE_Blue $\left(r=-0.58^{* *}\right)$, RE_Green $\left(r=-0.46^{* *}\right)$, RE_Red ( $r=-$ $\left.0.67^{* *}\right)$, PS_Blue $\left(r=-0.54^{* *}\right)$, PS_Green $\left(r=-0.43^{* *}\right)$, PS_Red $(r=-0.42 * *)$. Conclusions: It is recommended to use RE_Blue, RE_Green, RE_Red, PS_Blue, PS_Green, PS_Red satellite bands for the estimation of cotton leaf nitrogen content.

Significance and Impact of the Study: This study is of great importance in order to determine the need for nitrogen fertilizer usage in large cotton production areas. The study is important in terms of widespread impact and rapid results in large cotton production areas, especially considering the growing cotton cultivation areas in the GAP (South East Anatolia Project) region for optimum nitrogen fertilization in cotton production.
\end{abstract}

Atıf / Citation: Kılıçaslan S, Ekinci R, Başbağ S (2020) RapidEye ve PlanetScope uydu bantları ile pamuk bitkisi yaprak azot içeriğinin belirlenmesi. MKU. Tar. Bil. Derg. 25(2) : 169-180. DOI: 10.37908/mkutbd.654258

\section{GiRiş}

Pamuk; tekstil, yağ, yem ve kimya sanayi sektörleri başta olmak üzere birçok sanayi sektörünün hammaddesini oluşturmaktadır. Dünya nüfusunun artışı ile tüm sektörlere olan talep hızla artarken, pamuk üretim miktarlarında yeterli düzeyde artış sağlanamamaktadır. Pamuk, dünyada 85 kadar ülkede yetiştirilmesine (Başbağ ve ark., 2011) rağmen, 2019/2020 dönemi Eylül-
Ekim ayları itibari ile sırasıyla Hindistan (\%24.4), Çin (\%22.2), ABD (\%17.4), Brezilya (\%9.3), Pakistan (\%6.1), Türkiye (\%3.3) ve Özbekistan (\%2.4) en fazla üretim yapılan ülkeler olmuştur (USDA, 2019). Hindistan, Çin ve $A B D$, dünya toplam pamuk üretiminin $\% 64.08^{\prime}$ ini karşılamaktadır. 2018/2019 yılı verilerine göre Türkiye pamuk üretimi yönünden altıncı sırada (806 1000MT), yurt içi tüketimi yönünden altıncı sırada (1481 1000MT), ithalat yönünden beşinci sırada (762 1000MT), stok 
yönünden ise yedinci sırada (369 1000MT) bulunmaktadır. Verim değerlerine göre Çin, Brezilya ve Meksika'dan sonra dördüncü sırada (1549 kg/ha); ekim alanı yönünden ise on birinci sırada (0.52 milyon.ha) yer almaktadır (Aytaç ve ark., 2020). Bu durum, yıllara göre pamuk ve pamuk üretimine olan talebi daha da artırmaktadır. Türkiye'de pamuk; geniş kullanım alanı, oluşturduğu istihdam ve katma değer ile ülke ekonomisine büyük faydalar sağlayan önemli ve stratejik bir üründür.

Tüm bitkiler için önemli bir besin kaynağı olan azot (N), pamuk bitkisinin büyüme ve gelişiminde diğer makro ve mikro bitki besin elementlerine göre daha etkili olan, birçok farklı yollardan sağlanan, bitkilerde meydana gelen fizyolojik olaylarda görev alan, nitrat $\left(\mathrm{NO}_{3}{ }^{-}\right)$ve amonyum $\left(\mathrm{NH}_{4}^{+}\right)$iyon formlarında alınan hayati öneme sahip mobil bir bitki besin maddesidir (Kaçar, 2009) Bitkisel üretimde azota duyulan gereksinim ve kayıplar oldukça fazla ve aynı zamanda hızlı olduğundan eksikliği çok yaygındır. Vejetatif gelişme döneminde bitkide bulunma oranı/miktarı ve ihtiyaç oldukça yüksektir. Bitkilerin tür, çeşit, yaş, verim potansiyeli, kök, gövde ve yaprak yapılarına göre bitkideki miktarı ve ihtiyacı değişim göstermektedir (Kaçar ve Katkat, 2011).

Azotun (N) gerekli olan miktardan daha az alımı durumunda, bitki, vejetatif ve generatif olarak yeterli düzeyde büyüme ve gelişme sağlayamamakta; fazla kullanılması durumunda ise insan sağlığına ve çevre kirliliğine olumsuz yönde etki etmektedir (Sutton ve ark., 2011) Bioçeşitliliğin azalması, sularda nitrat oranında artış, asidifikasyon, azot-oksit emisyonu sonucunda küresel ısınma ve stratosferik ozon tabakasının incelmesi, ekolojik faktörlerin değişimi, ve iklim değişimi insanoğlunun yaşamı ve sağlığını olumsuz etkilemektedir.

Yapılan araştırmalarda pamuk yetiştiriciliğinde azotlu gübreleme çalışmalarında yüksek pamuk kütlü veriminin $15-20 \mathrm{~kg} / \mathrm{da}$ dozunda alındığı (Rochester, 2007; Bibi ve ark., 2011; Hakoomat ve Raheel, 2011; Seilsepour ve Rashidi, 2011; Hernández-Cruz ve ark., 2015) azot dozundaki artışla koza sayısı ve koza ağırlığının arttığı böylece pamuk veriminde artışa neden olduğu (Hakoomat ve Raheel, 2011) ve en iyi lif kalite parametreleri için $24 \mathrm{~kg} /$ da dozun ideal uygulama dozu olduğu (Zhao ve ark., 2012) saptanmıştır. Ancak çok büyük alanlarda bitkinin gübre ihtiyacının belirlenmesi büyük zorluklar içermekte, maliyetli olmasının yanında zaman almakta ayrıca bitkiye de belirli oranda zarar vermektedir. Bu amaçla bitkinin azot ihtiyaç durumunun optik sensorlar yardımıyla belirlenmesi günümüz teknoloji kullanımı yönünden büyük önem taşımaktadır (Cassman ve ark., 2002; Raun ve ark., 2002; Mullen ve ark., 2003; Chartuni ve ark., 2007; Bagheri ve ark., 2013; Yousefi ve Razdari. 2014; Esetlili ve ark., 2015)

Tarımsal üretimde gübre kayıplarının azaltılması için uygulanacak gübre dozlarının bitki ihtiyacına göre belirlenmesi gerekmektedir. Bu amaçla bitki ihtiyacının belirlenmesi için toprak veya yaprak analizi en fazla uygulanan yöntemlerdendir. Bitkinin azot başta olmak üzere diğer birçok bitki besin maddelerinin anlık durumları ve gereksinim miktarlarının saptanmasına yönelik yeni teknolojilerin kullanımı ve yeni hesap yöntemlerinin geliştirilerek doğru tahmin edilmesi tarımsal üretim ve çevreye daha duyarlı üretim için önemlidir.

Hassas tarım; ürün ekilişinden hasadına kadar geçen sürede, konumsal ve zamansal açıdan farklılık gösteren gereksinimlere, bu konum ve zaman kriterleri dikkate alınarak yapılması gereken müdahaleyi bir bilgi ve kontrol sistemi kullanarak yapan sistemdir (Türker ve ark., 2015; Keskin ve ark., 2018). Hassas tarımda, kaynak/kullanım dengesi ve üretimde sürdürülebilirlik gözetilerek üründen elde edilecek geliri maksimize etmek amaçlanmaktadır. Bu amaçlarla hassas tarımda Coğrafi Bilgi Sistemi ve Uzaktan Algılama yöntemleri kullanılmaktadır. Coğrafi Bilgi Sistemi; konumsal bilgileri toplama, saklama, analiz etme ve benzeri işlemleri yapabilme yeteneğine sahip bilgi sistemi (Yousefi ve Razdari, 2014; Çabuk ve ark., 2019), Uzaktan Algılama ise; yeryüzündeki herhangi bir cisimden yayılan ya da yansıyan ışınımın özellikleri hakkında arada herhangi bir fiziksel temas olmaksızın çeşitli algılayıcılar vasıtası ile bilgi toplanması yöntemi olarak tanımlanabilir (Sunar ve ark., 2018).

Uzaktan algılama, bitkinin yeşil aksamında oluşan fizyomorfolojik özelliklerin değişiminin ortaya konulması ve geniş alanlarda anlık tahmin etmede hataların azaltılması yönünden önemli veriler ortaya koyabilmektedir (Mutanga ve ark., 2004). Nesnelere doğrudan dokunmadan uzaktan yapılabilecek ölçümler ile nesneler hakkında bilgi edinmeye olanak sağlayan uzaktan algılama sistemleri yakın zaman içerisinde başta tarım olmak üzere birçok alanda başarılı şekilde kullanılmaktadır (Wright ve ark., 2005). Bitki besin maddelerinin eksikliğinde oluşan renk ve yansıma farklılıkları doğrudan bitkilerin spektral yansıma değerlerine etkide bulunmaktadır (Carter ve Knapp, 2001). Bu yöntemler geniş alanlarda veri üretirken bitkiye ve çevreye zararlı etkileri bulunmamaktadır.

$\mathrm{Bu}$ çalışma, pamuk bitkisi yaprak azot içeriğinin belirlenmesinde RapidEye (RE) ve PlanetScope (PS) uydu görüntülerinin kullanılabilirliğini araştırmak, uydu verileri ile yaprak azot içeriğini tahmin etmede uzaktan algılama yönteminin kullanılabilirliğini test etmek, 
pamuk bitkisinde azot intiyacı belirleme ve azotlu gübre miktarı tavsiyesinde uzaktan algılama yönteminin uygulanabilirliğini belirlemek amacı ile yürütülmüştür.

\section{MATERYAL ve YÖNTEM}

\section{Çalışma Yerinin Özellikleri}

Mardin ekolojik koşullarında yürütülen bu çalışmada, Gossypium hirsutum L. türüne ait ST-468 pamuk çeşidi bitkisel materyal olarak kullanılmıştır. Çalışma Mardin ili Artuklu ilçesi Küçükköyü (Küçükköy-1, Küçükköy-2 ) ve Kızıltepe ilçesi Tanrıverdi köyü (Tanrıverdi-1, Tanrıverdi2, Tanrıverdi-3, Tanrıverdi-4 ) sınırlarında olmak üzere toplam 6 lokasyonda yürütülmüştür.

Çalışma, tesadüf parselleri deneme deseninde her lokasyonda 3 tekerrürlü olmak üzere 30 parselde yürütülmüştür. Her parsel $50 \mathrm{~m}$ uzunluk ve $17.5 \mathrm{~m}$ genişliğinde olacak şekilde yapılandırılmıştır. Deneme yerinin, siltli killi toprak yapısına, tuz oranı bakımından normal değerlere, $\mathrm{pH}$ ve kireç oranı bakımından çok yüksek seviyeye, fosfor ve çinko bakımından yetersiz duruma ve potasyum ve demir içeriği bakımından yeterli bir seviyeye sahip olduğu belirlenmiştir (Çizelge 1). Çalışma yerinde karasal iklim hâkim olup, yazları çok sıcak ve kurak, kışları ise ılıman olup, yıllık yağış ortalaması $350 \mathrm{~mm}$ 'dir. Bölgede genellikle kuraklıklar yaşanmaktadır. Kızıltepe ve Artuklu ilçelerinde nemlilik düzeyi oldukça düşüktür. Tüm lokasyonlarda ön bitki olarak ana ürün buğday ve ikinci ürün olarak danelik mısır ekilmiştir. Mısır bitkisine $35 \mathrm{~kg} / \mathrm{da}$ 20.20.0 (NPK) kompoze ve $50 \mathrm{~kg} / \mathrm{da} \% 33$ amonyum nitrat gübresi uygulanmıştır. Pamuk ekimi 26 Nisan 2018 tarihinde makine ile dekara $2.5 \mathrm{~kg} / \mathrm{da}$ tohum kullanılarak yapılmıştır. Tüm parsellere ekim ile beraber 20.20.0 (NPK) kompoze gübre $45 \mathrm{~kg} / \mathrm{da}$ olarak uygulanmıştır. Uygulama parsellerinde toprak ve yaprak azot oranı değişkenliği oluşturmak için 25 Haziran 2018 tarihinde (ekimden 60 gün sonra) Üre (\%46 N) formunda $0,10,15$, $20,25,30,35,40,45$ ve $50 \mathrm{~kg} /$ da dozlarında gübreleme uygulanmıştır. Uydu görüntüleri çekim tarihi (25.07.2018) (ekimden 90 gün sonra) ile aynı günde her parselden rastgele 25 adet yaprak örneği alınmıştır. Örneklemede en üst beşinci boğumda (normal büyüklüğe ulaşmış, gelişmesini tamamlamış genç yaprak) bulunan yapraklar koparılarak alınmış, delikli naylon torbalara konularak parsel bilgisi ile etiketlenmiştir.

Denemenin yürütüldüğü lokasyonlara ait ekim öncesi alınan toprak örneklerinin analiz sonuçları Çizelge 1 'de verilmiştir.

Çizelge 1. Denemenin yürütüldüğü parsellere ait toprak analiz sonuçları

Table 1. Soil analysis results of the experiment area

\begin{tabular}{|c|c|c|c|c|c|c|c|}
\hline Lokasyonlar & $\mathrm{pH}$ & Tuz (\%) & Kireç (\%) & Tekstür & $\begin{array}{c}\text { Organik } \\
\text { Madde (\%) }\end{array}$ & $\begin{array}{c}\mathrm{P}_{2} \mathrm{O}_{5}(\mathrm{mg} \\
\left.\mathrm{kg}^{-1}\right)\end{array}$ & $\begin{array}{c}\mathrm{K}_{2} \mathrm{O}(\mathrm{mg} \\
\left.\mathrm{kg}^{-1}\right)\end{array}$ \\
\hline $\begin{array}{l}\text { Tanriverdi-1 } \\
\left(37^{\circ} 4^{\prime} 47.43^{\prime \prime K} \text { - } 40^{0} 35^{\prime} 18.63^{\prime \prime D}\right)\end{array}$ & 7.9 & 4.2 & 9.1 & Siltli-Killi & 1.9 & 9.4 & 131 \\
\hline $\begin{array}{l}\text { Tanriverdi-2 } \\
\left(37^{\circ} 4^{\prime} 39.51^{\prime \prime} \mathrm{K}-40^{0} 35^{\prime} 13.53^{\prime \prime} \mathrm{D}\right)\end{array}$ & 8.1 & 4.7 & 8.6 & Siltli-Killi & 2.2 & 10.0 & 136 \\
\hline $\begin{array}{l}\text { Tanriverdi-3 } \\
\left(37^{0} 5^{\prime} 1.12^{\prime \prime} \mathrm{K}-40^{0} 35^{\prime} 13.28^{\prime \prime} \mathrm{D}\right)\end{array}$ & 8.2 & 5.3 & 9.0 & $\begin{array}{l}\text { Siltli-Killi- } \\
\text { Tın }\end{array}$ & 2.3 & 8.8 & 158 \\
\hline $\begin{array}{l}\text { Tanriverdi-4 } \\
\left.\text { (370 } 5^{\prime} 9.96^{\prime \prime} \mathrm{K}-40^{0} 35^{\prime} 6.46^{\prime \prime} \mathrm{D}\right)\end{array}$ & 8.2 & 5.0 & 8.7 & $\begin{array}{l}\text { Siltli-Killi- } \\
\text { Tın }\end{array}$ & 2.5 & 9.2 & 166 \\
\hline $\begin{array}{l}\text { Küçükköy-1 } \\
\left(37^{\circ} 7^{\prime} 59.89^{\prime \prime} \mathrm{K}-40^{\circ} 51^{\prime} 24.21^{\prime \prime} \mathrm{D}\right)\end{array}$ & 8.6 & 5.6 & 8.9 & Siltli-Killi & 2.2 & 11.1 & 175 \\
\hline $\begin{array}{l}\text { Küçükköy-2 } \\
\left(37^{0} 8^{\prime} 18.15^{\prime \prime} \mathrm{K}-40^{0} 51^{\prime} 22.35^{\prime \prime} \mathrm{D}\right)\end{array}$ & 8.5 & 5.1 & 8.9 & Siltli-Killi & 2.4 & 10.6 & 183 \\
\hline
\end{tabular}

\section{Yaprak azot içeriği analizi}

Çalışmada, alınan yaprak örnekleri etüvde $70^{\circ} \mathrm{C}^{\prime}$ de 48 saat kurutulduktan sonra yaprak azot içeriği (YAi) (\%) FOSS marka XDS model NIR cihazı ile (FOSS, Eden Prairie, Kuzey Amerika) AOAC 992-23 yöntemine göre belirlenmiştir (Anonim, 1990). Yaprak azot içeriğinin \%3.50-\%5.02 arasında değiştiği belirlenmiş ve bu veriler 20 adet sınıf (Çizelge 2) oluşturularak irdelenmiştir. Sınıf aralığı \%0.075 alınmıştır.

\section{Uzaktan algılama uydu verileri}

Çalışmada veriler ve elde edilen RapidEye ve PlanetScope uydularına ilişkin teknik özellikler Çizelge 3 'te verilmiştir. Bu uydular yüksek çözünürlük (5 m ve altı) sınıfına girmeleri, bu sınıftaki uydulara göre maliyet açısından daha uygun olmaları ve istenilen zaman aralığında çekim yapabilme kabiliyetlerinin yüksek olması nedeniyle seçilmiştir. 
Çizelge 2. Yaprak Azot içeriği sınıf değerleri

Table 2. Leaf nitrogen content values

\begin{tabular}{|c|c|c|c|c|c|}
\hline \multirow{2}{*}{ Azot Skala Sınıfı } & \multicolumn{2}{|c|}{ Yaprak Azot Değeri (\%) } & \multirow{2}{*}{ Azot Skala Sınıfı } & \multicolumn{2}{|c|}{ Yaprak Azot Değeri (\%) } \\
\hline & Alt Sınır Değeri & Üst Sınır Değeri & & Alt Sınır Değeri & Üst Sınır Değeri \\
\hline 1 & 3.500 & 3.575 & 11 & 4.260 & 4.335 \\
\hline 2 & 3.576 & 3.651 & 12 & 4.336 & 4.411 \\
\hline 3 & 3.652 & 3.727 & 13 & 4.412 & 4.487 \\
\hline 4 & 3.728 & 3.803 & 14 & 4.488 & 4.563 \\
\hline 5 & 3.804 & 3.879 & 15 & 4.564 & 4.639 \\
\hline 6 & 3.880 & 3.955 & 16 & 4.640 & 4.715 \\
\hline 7 & 3.956 & 4.031 & 17 & 4.716 & 4.791 \\
\hline 8 & 4.032 & 4.107 & 18 & 4.792 & 4.867 \\
\hline 9 & 4.108 & 4.183 & 19 & 4.868 & 4.943 \\
\hline 10 & 4.184 & 4.259 & 20 & 4.944 & 5.019 \\
\hline
\end{tabular}

Çizelge 3. RapidEye ve PlanetScope Uydularına İlişkin Teknik Özellikler (Anonim 2019)

Table 3. Technical specifications of RapidEye and PlanetScope Satellite

\begin{tabular}{llll}
\hline Özellikler & RapidEye (RE) & PlanetScope (PS) \\
\hline Uydu Sayısı & & 5 & - \\
Yörünge Yüksekliği & & $630 \mathrm{~km}$. Sun-synchronous & $475 \mathrm{~km}$. \\
Ekvator Geçiş Zamanı & Blue & $11: 00 \mathrm{am}$ (tahmini) & $9: 30-11: 30 \mathrm{am}$ \\
& Green & $440-510$ & $455-515$ \\
Spektral Bantlar (nm) & $520-590$ & $500-590$ \\
& Red & $630-685$ & $590-670$ \\
& NIR & $760-850$ & $780-860$ \\
Yersel Örnekleme mesafesi (nadir) & $690-730$ & - \\
Piksel Boyutu (ortorektifiye edilmiş) & $6.5 \mathrm{~m}$ & $3.7 \mathrm{~m}$ \\
Çerçeve Genişliği & $5 \mathrm{~m}$ & $3.7 \mathrm{~m}$ \\
Yeniden geçiş zamanı & $77 \mathrm{~km}$ & $24.6 \mathrm{~km} \times 16.4 \mathrm{~km}$ \\
Dinamik Aralığı & $5.5 \mathrm{gün}$ (Nadir), Her gün (Off-nadir) & Her gün (nadir) \\
\hline
\end{tabular}

\section{Uydu Görüntüleri İşleme Protokolü}

25 Temmuz 2018 tarihli RapidEye (RE) ve PlanetScope (PS) uydu görüntüleri Nik Inşaat Tic. Ltd. Şti. isimli firmadan (Mecidiyeköy, İstanbul) temin edilmiştir. Görüntüler orthorektifiyeli olarak temin edildiğinden herhangi bir geometrik düzeltme işlemi uygulanmamıştır. Uydu görüntülerine yapılan işlemlere ilişkin iş akış protokolü Şekil 1'de verilmiştir. Fotoğraflara TNT Mips (Microlmages, Inc., Nebraska, ABD) yazılımı ile kontrast düzeltme işlemi yapılmış, ardından bulut, nem, sis gibi harici etkileri ortadan kaldırmak amacıyla $\mathrm{PCl}$ Geomatica (PCl Geomatics, Markham, Kanada) programı ile atmosferik düzeltme işlemi uygulanmıştır. Görüntülerin hücre piksel değerleri Smoothing (lowpassing) filtre ( $3 \times 3)$ ile filtrelenerek elde edilen değerler
Microsoft Excel-2013 (Microsoft, Washington, ABD) formatında deneme parsel numaraları ve uydu bant sırasına göre kaydedilmiştir.

\section{istatistik analiz}

Çalışma kapsamında incelenen yaprak azot içeriği ile uydu verileri arasındaki ilişkilerin (basit korelasyon katsayıları) korelasyon analizi yapılarak, istatistiki olarak yaprak azot içeriği-yansıma arası ikili ilişki (korelasyon) analizleri önemli olduğu saptanan bantlar için regresyon (yaprak azot içeriği-yansıma) ve ters regresyon (yansımayaprak azot içeriği) analizleri yapılmıştır. İstatistiki analizler, JMP 5.0.1 paket programı (Copyright (C) 19892002 SAS Institute Inc.) yardımı ile yapılmıştır. 


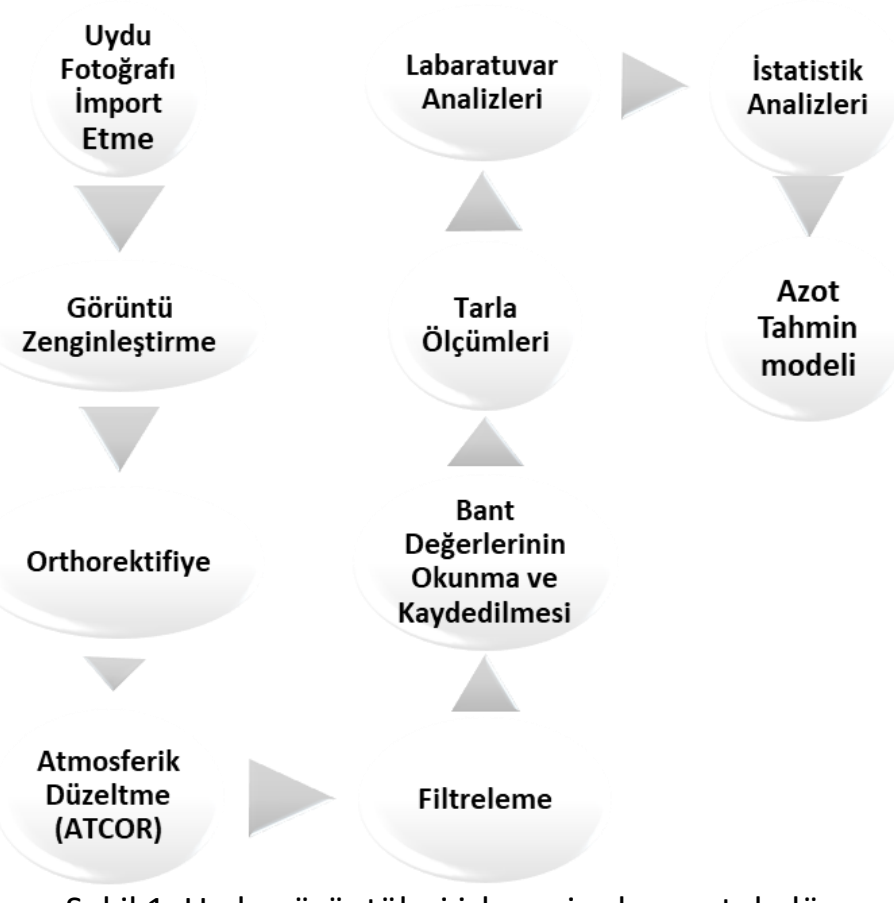

Şekil 1. Uydu görüntüleri işleme iş akış protokolü

Figure 1. Satellite image processing flowchart protocol

\section{BULGULAR ve TARTIŞMA}

Pamuk yaprak azot içeriği (\%) ve incelenen uydu bantları yansıma değerleri arasındaki ikili ilişkiler (korelasyon katsayıları), regresyon ve ters regresyon analiz sonuçları Çizelge 4'de verilmiştir.

Çizelge 4. Yapraktaki azot içeriği (\%) ve incelenen uydu bantları arasındaki ikili ilişkiler (korelasyon katsayıları), regresyon ve ters regresyon analiz sonuçları

Table 4. Binary relationships (correlation coefficients) between the nitrogen content in the leaf (\%) and satellite bands, regression and inverse regression analysis results

\begin{tabular}{|c|c|c|c|c|c|c|}
\hline Bant & I & $r$ & Regresyon & Ters Regresyon & $\mathbf{R}^{2}$ & RMSE \\
\hline RE_Blue & -0.58 & $* *$ & $y=67.08 * N^{2}-632.67 * N+1950.13$ & $\mathrm{~N}=-0.00003 *$ RE_Blue ${ }^{2}+0.02440 *$ RE_Blue-0.67 & 0.38 & 0.23 \\
\hline RE_Green & -0.46 & $* *$ & $y=128.66 * N^{2}-1144.41 * N+3394.14$ & $\begin{array}{l}\mathrm{N}=-0.00002 * \mathrm{RE} \_\mathrm{Green}^{2}+0.03618 * \mathrm{RE} \_ \text {Green- } \\
10.34\end{array}$ & 0.28 & 0.26 \\
\hline RE_NIR & -0.14 & $*$ & $y=-0.05 * N^{2}+0.42 * N-0.18$ & $N=-44.13 * N I R \_R E^{2}+71.49 * N I R \_R E-24.60$ & 0.21 & 0.29 \\
\hline RE_Red & -0.67 & $* *$ & $\begin{array}{l}y=258.98 * N^{2}- \\
2 * 382.98 * N+6179.39\end{array}$ & $\begin{array}{l}\mathrm{N}=- \\
0.000005 * R E \_R e d^{2}+0.005411 * R E \_R e d+2.83\end{array}$ & 0.50 & 0.21 \\
\hline RE_Rededge & -0.23 & $*$ & $y=-61.58 * N+2 * 245.09$ & $\mathrm{~N}=-0.001 * \mathrm{RE} \_$RedEdge +5.900 & 0.05 & 0.29 \\
\hline PS_Blue & -0.54 & $* *$ & $y=-62.69 * N+722.69$ & $\mathrm{~N}=-0.005^{*}$ PS_Blue +6.40 & 0.30 & 0.25 \\
\hline PS_Green & -0.43 & $* *$ & $y=-60.89 * N+1176.12$ & $\mathrm{~N}=-0.003 *$ PS_Green+7.03 & 0.18 & 0.25 \\
\hline PS_NIR & 0.10 & öd & & & & \\
\hline PS_Red & -0.42 & $* *$ & $y=92.25 * N+1453.98$ & $\mathrm{~N}=-0.002 *$ PS_Red +6.316 & 0.18 & 0.27 \\
\hline
\end{tabular}

*:\%1 düzeyinde önemli; ${ }^{* *} \% 5$ düzeyinde önemli; öd: önemli değil; RMSE: Hata Kare Ortalamalarının Karekökü

Yaprak azot içeriği ile incelenen RE_Blue $\left(r=-0.58^{* *}\right)$, RE_Green $\left(r=-0.46^{* *}\right)$, RE_NIR $\left(r=-0.14^{*}\right)$, RE_Red $(r=-$ $\left.0.67^{* *}\right)$ ve RE_Rededge $\left(r=-0.23^{*}\right)$ RapidEye uydu bantları yansıma değerleri ile PS_Blue $\left(r=-0.54^{* *}\right)$, PS_Green $\left(r=-0.43^{* *}\right)$ ve PS_Red $\left(r=-0.42^{* *}\right)$ PlanetScope uydu bantları yansıma değerleri arası negatif ve önemli düzeyde ikili ilişkiler (korelasyon) saptanırken, PS_NIR $(r=+0.10)$ PlanetScope uydu bandı yansıma değeri arasında ise pozitif ve önemli düzeyde ikili ilişkiler saptanmıştır (Çizelge 4).

Elde ettiğimiz bulgular, buğday (Triticum aestivum L.)

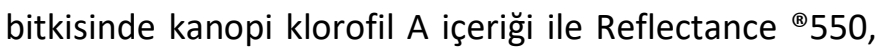
R680 ve tüm kırmızı kenar (Red Edge) parametreleri arasında anlamlı korelasyon saptandığını ve optik tekniklerin kullanılmasıyla, buğdayın $\mathrm{N}$ durumunu belirlemek/değerlendirmek için bir yöntem olarak 
kullanılabileceğini bildiren Filella ve ark. (1995); pamuk bitkisi yaprak $\mathrm{N}$ içeriği, yaprak klorofil içeriği ve azot içeriği arasında zayıf korelasyonun ( $r=+0.32)$ saptandığını, yaprak klorofil ve R415/R695 arasında olumlu ( $r=+0.72$ ); yaprak azot içeriği ile $R 415 / R 710$ arasında olumlu $(r=+0.70)$ korelasyon saptandığını; pamukta $\mathrm{N}$ durumunun uzaktan algılanmasının, spektrumun menekşe (Violet) veya mavi (Blue) bölgesi (400 450 nm) ile Kırmızı Kenar (Red Edge) (690-730 nm) bölgesinin yansıma oranları kullanılarak yapılabileceğini bildiren Read ve ark. (2002); pamuk bitkisi N durumunu maksimum \% 77 oranında tahmin edilebildiğini bildiren Fridgen ve Varco (2004); erken dönem buğday azot (N) durumunu değerlendirmek için Karasal LiDAR (TLS)'ın uygunluğu test etmek amacıyla yapılan çalışmada, \%N ile TLS arasında zayıf $\left(R^{2}=0.10-0.75\right)$, azot beslenme indisi (NNI) ile TLS arasında orta $\left(R^{2}=0.45-0.54\right)$ derecede ilişki bulduğunu bildiren Eitel ve ark. (2014); uzaktan algılama görüntüsü işleme tekniği kullanılarak yapılan çalışmada tekniğin bitkide klorofil ve azot tahmini için oldukça kullanışlı olduğu bildiren Patane ve Vibhute (2014); çeltik bitkisinde azot kullanım durumunu belirlemek amacıyla FORMOSAT-2 uydu görüntülerini kullanılarak azot beslenme indisinin (The Nitrogen Nutrition Index) (NNI) tahmini için yapılan çalışmada, vejetasyon indisleri ile direkt olarak NNI değişkenliğinin \%45'ini açıklanabilir olduğunu, bitki azot alımı PNU (Plant Nitrogen Uptake) yoluyla NNI değişkenliğinin \%52'sinin açıklanabildiğini bildiren Huang ve ark. (2015); buğday bitkisinde RapidEye görüntüleri kullanarak çeşitli vejetasyon indislerin hesaplanması amacıyla yapılan çalışmada, bitkinin yaşlanmasıyla birlikte değişen klorofil miktarının, bu indislerle korelasyon gösterdiğini bildiren Schönert ve ark. (2015); çeltik bitkisinde uydu görüntüleri kullanılarak azot durumunu belirlemek amacıyla yapılan çalışmada, Red-Edge tabanlı vejetasyon indisleri ile toprak üstü biokütle (AGB: above ground biomass) değişkenliğini \%53-64, bitki azot alımı PNU (plant $\mathrm{N}$ uptake) değişkenliğini \%62-65 oranında açıklayabildiğini; performans yönünden WorldView-2, RapidEye ve Formosat-2 sıralamasının oluştuğunu bildiren Huang ve ark., (2017)'nın bulguları ile benzerlik göstermektedir. Oysaki pamuk bitkisinde spektrarodyometre kullanarak yaptıkları çalışmada, R517/R413 nm'deki yansıma değerlerinin yaprak $N$ konsantrasyonuyla $\left(R^{2}=065 / 078\right)$, R708 / R915 veya R551 / R915'in yansıtma oranlarının yaprak klorofil konsantrasyonu ile $\left(R^{2}=0.67-0.76\right)$ yakından ilişkili olduğunu bildiren Zhao ve ark. (2005); SPOT-2 ve LANDSAT uydu görüntüleri ve el spektroradyometresi kullanılarak yapılan çalışmada, pamuk ve buğday bitkilerinde azot miktarları ile NIR arasında istatistiki olarak önemli (\%5) ilişki saptandığı bildiren Eroğlu (2008); mısır ve buğday bitkilerinde Double-peak Canopy Nitrogen Index (DCNI) adlı yeni bir vejetasyon indisi üreterek, bu indisin bitki $\mathrm{N}$ konsantrasyonunu tahmin etmek için iyi bir potansiyele (mısır için $R^{2}=0.72$, buğday için $R^{2}=0.44$ ) sahip olduğunu bildiren Chen ve ark. (2010); buğday (Triticum aestivum L.) bitkisinde farklı azot dozlarının, çeşitli bitki parametreleri üzerindeki etkisinin sensörler arasında farklılık gösterdiğini; biokütle parametreleri ile $\mathrm{N}$ dozları arasında yüksek ilişki ( $r=+0.96)$ bulunduğunu; yakın kızılötesi (NIR) tabanlı indislerin (R760/R730), buğdayın $\mathrm{N}$ durumunu gösteren en güçlü ve kararlı indis olduğunu bildiren Erdle ve ark. (2011); mısır bitkisinde erken evrelerde zayıf korelasyon, çiçeklenme evresinde en yüksek korelasyon ve olgunlaşma safhalarında yavaşça azalan korelasyon bulduğunu bildiren Spitkó ve ark. (2016)'nın bulgularından farklılık göstermektedir. Bu durum, çalışmanın bitkisel materyalleri, ekolojik koşullar ve çalışmada kullanılan metottan kaynaklanmış olabileceği düşünülmektedir.

Yaprak azot içeriği (\%) ile incelenen uydu bantları yansıma değerleri regresyon analiz sonuçlarına göre düşük seviyede ilişki gösteren $\left(R^{2}<0.18\right) R E \_$Rededge uydu bandına ait denklemin pamuk bitkisi yaprak azot içeriğinin tahmini için kullanılmaması önerilmektedir.

Elde ettiğimiz bulgular, pamuk bitkisinin ilk çiçeklenme döneminde SCCCl ile bitki N\% 'sindeki değişkenliği saptamada en iyi performans gösteren endeks olduğu; bitki $\mathrm{N}$ durumunu ayırt etme konusundaki endeks performansı iyileştiğini belirten Ballester ve ark., (2017); buğday bitkisinde kanopi klorofil indisi (CCI) ile kanopi azot indisi'ni (CNI) birleştirerek, alan başına düşen azot miktarı $\left(\mathrm{g} / \mathrm{m}^{2}\right)$ cinsinden, daha güçlü bir şekilde ilişkili olduğunu bildiren Fitzgerald ve ark. (2010); kış buğdayının (Triticum aestivum L.) bitkisi N konsantrasyonunudaki değişimin, erken evrelerde modifiye klorofil absorpsiyon oranı indisinin (MCARI) $\% 22^{\prime}$ sini ve R763 / R761'in \%43'ünü, geç büyüme aşamalarında R700 / R670'ın \%51'ini ve R418 / R405 'in \%57'sini açıklayabileceğini; kırmızı kenar (Red Edge) ve yakın kızıötesi (NIR) bantlarının erken evrelerde PNC tahmini için daha etkili olduğunu; görünür bantların, özellikle morötesi, menekşe (Violet) ve mavi (Blue) bantların geç evrelerde daha duyarlı olduğunu bildiren $\mathrm{Li}$ ve ark. (2010); pamuk bitkisinde dijital kamera ve spektrometre kullanarak dijital kamera indisleri (DI) ile önemli derecede ilişki bulduğunu (DI (R580, R680) için $R^{2}=0.81$ ve $G-R$ için $R^{2}=0.76$ ) bildiren Wang ve ark. (2011); hiperspektral görüntüler kullanarak, laboratuvar ve tarla koşullarında uygun kalibrasyon ile yaprak azot konsantrasyonunu tahmin etmek amacıyla yapılan çalışmada, hiperspektral görüntüleme yönteminin ümit 
verici $\left(R^{2}=0.875\right)$ bir teknoloji olduğunu bildiren Vigneau ve ark. (2011); çeltik bitkisinde Green, Red Edge ve NIR bantlarına sahip Crop Circle aktif kanopi sensörü kullanılarak yapılan çalışmada, 43 farklı vejetasyon indisi ile yapılan değerlendirmede MCARI1 indisinin büyüme aşamaları boyunca bitki toprak üstü biokütlesini $\left(R^{2}=0.79\right)$ ve bitki azot alımını $\left(R^{2}=0.83\right)$ tahmin edebildiğini bildiren Cao ve ark. (2013); mısır bitkisinde Temel Bileşen Analizi yöntemine (Principal Component Analysis) ve Geri Yayılım Yapay Sinir Ağı (Back Propagation Artificial Neural Network) modeline dayandırdığı tahmin yönteminin faydalı $\left(R^{2}=0.81\right)$ bir araç olduğunu bildiren Chen ve ark. (2013); buğday azot (N) durumunu değerlendirmek için Karasal LiDAR (TLS) 'ın uygunluğu test etmek amacıyla yapılan çalışmada, \%N ile TLS arasında zayıf $\left(R^{2}=0.10-0.75\right)$, azot beslenme indisi (NNI) ile TLS arasında orta $\left(R^{2}=0.45-0.54\right)$ derecede ilişki bulduğunu bildiren Eitel ve ark. (2014); uzaktan algılama görüntüsü işleme tekniği kullanılarak yapılan çalışmada tekniğin bitkide klorofil ve azot tahmini için oldukça kullanışlı olduğu bildiren Patane ve Vibhute (2014); buğday bitkisinde Sentinel-2 uydu görüntülerini kullanarak bitkide azot beslenme indisinin (The Nitrogen Nutrition Index) (NNI) tahmin edilmesi amacı ile yapılan çalışmada, çeşitli bant kombinasyonları denenmiş ve $\mathrm{S}$ bant setlerinin önemli olabileceğini bildiren Delloyea ve ark. (2018); buğday bitkisinde, azot eksikliğinin çeşitli durumları ile spektral indislerin bu etkileşimlere bakılmaksızın verim, toprak üstü biokütle ve azot alımı ile ilgili güvenilir bir tahmin sağladığını bildiren Klema ve ark. (2018)'ın bulgularını desteklerken, patates bitkisinde hiperspektral verilerle simule ettiği PROSAIL radyasyon transfer modeli kullanılarak Red-Edge tabanlı klorofil indislerinin Kanopi klorofil içeriği ile doğrusal ilişkili $\left(R^{2}=0.94\right)$ olduğunu gösteren Clevers ve Kooistra (2012); buğday bitkisinde Normalleştirilmiş fark kırmızı kenar indisinin (The normalized difference red-edge index) (NDRE) buğday azot alımının \%81'ini açıklayabileceği bildiren Magney ve ark. (2016)'ın bulgularından farklılık göstermektedir. Bu durum, çalışmanın bitkisel materyalleri, ekolojik koşullar ve çalışmada kullanılan metot farklıı̆̆ından kaynaklanmış olabileceği düşünülmektedir.

Pamuk bitkisi yaprak azot içeriği (\%) ile incelenen RE_Blue $\left(R^{2}: 0.38\right), R E \_G r e e n\left(R^{2}: 0.28\right), R E \_N I R\left(R^{2}: 0.21\right)$, RE_Red $\left(R^{2}: 0.50\right)$, PS_Blue $\left(R^{2}: 0.29\right), P S \_G r e e n\left(R^{2}: 0.18\right)$ ve PS_Red $\left(R^{2}: 0.18\right)$ uydu bantları tahmin edilebileceğini ortaya koymuştur (Çizelge 4; Şekil 2a, 2c, 2e, 2g, 3a, 3c, 3e).

Uydu yansıma değerinden pamuk bitkisinin yaprak azot (N) içeriğini tahmin etmek için yapılan ters regresyon analizinde, RE_Blue $\left(R^{2}=0.38\right) ; R E$ Green $\left(R^{2}=0.28\right)$, RE_NIR $\left(R^{2}=0.21\right), R E \_R e d\left(R^{2}=0.50\right), P S \_B l u e\left(R^{2}=0.29\right)$, PS_Green $\left(R^{2}=0.18\right), P S \_R e d \quad\left(R^{2}=0.18\right)$ önemli ters regresyon analiz sonuçları elde edilmiştir (Çizelge 4; Şekil $2 b, 2 d, 2 f, 2 h, 3 b, 3 d, 3 f)$.

Sonuç olarak; pamuk yaprak azot içeriği (\%) ile incelenen uydu bantları yansıma değerleri arasındaki regresyon analiz sonuçlarına göre; düşük ve orta seviyede anlamlı ilişki ifade eden ya da edebilecek olan $\left(R^{2}=>0.18\right)$ RE Blue, RE Green, RE Red, RE NIR, PS Blue, PS Green, PS Red uydu bantları kullanılarak pamuk bitkisi yaprak azot içeriğinin uzaktan algılama yöntemi ile tahmini için kullanılabileceği saptanmış ve önerilmektedir. 

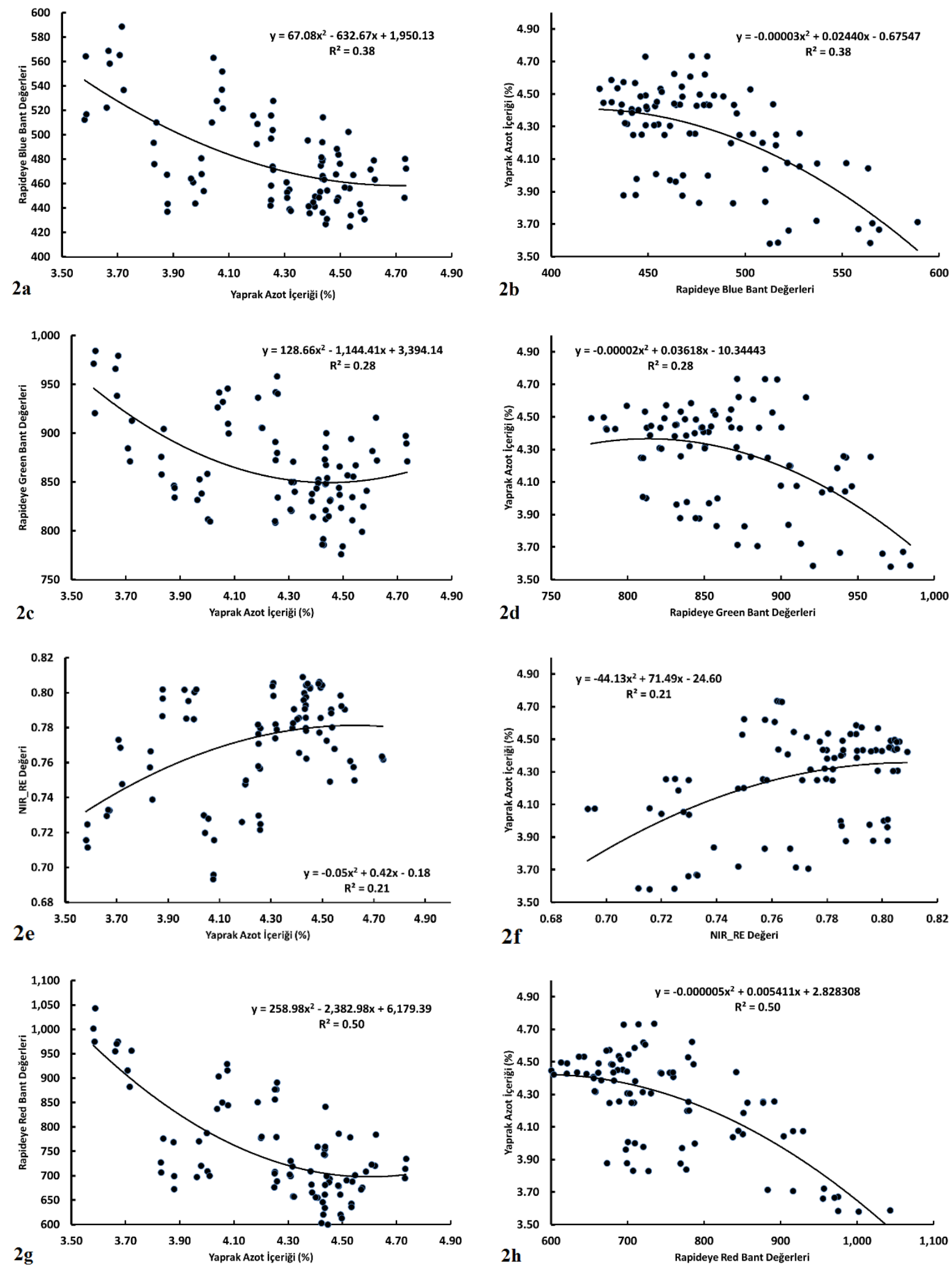

Şekil 2. Pamuk YAi (\%) ile RapidEye (RE) uydu verileri arası regresyon analiz sonuçları Figure 2. Regression analysis results between Cotton LNC (\%) and RapidEye (RE) satellite data 

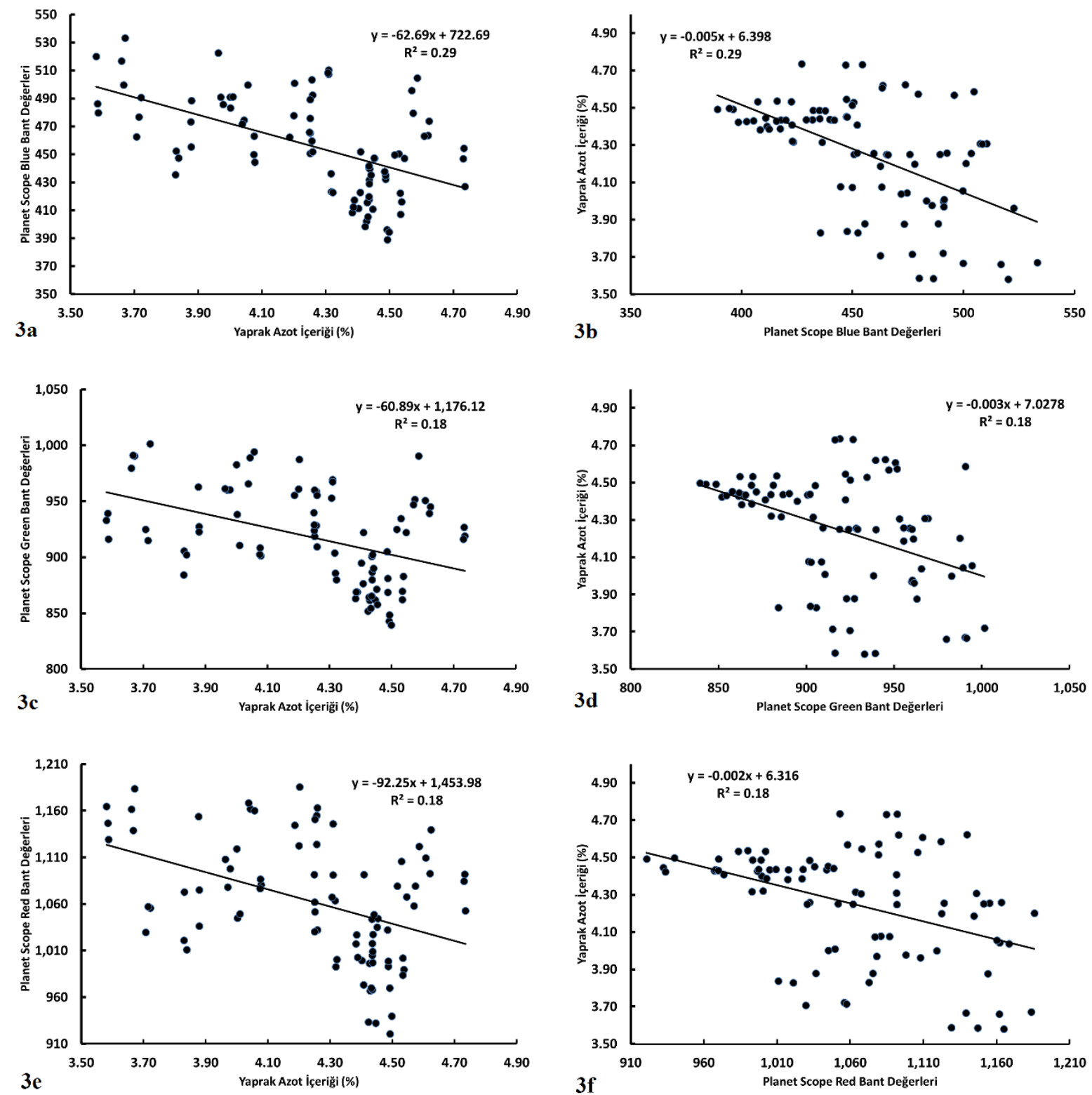

Şekil 3. Pamuk YAi (\%) ile PlanetScope (PS) uydu verileri arası regresyon analiz sonuçları

Figure 3. Regression analysis results between Cotton LNC (\%) and PlanetScope (PS) satellite data

\section{ÖZET}

Amaç: Bu çalışma, pamuk bitkisinin farklı yaprak azot içeriklerinin uydu görüntülerinde oluşan değişimlerini saptamak, uydu görüntüleri yardımı ile yapraktaki azot içeriğini tahmin etmek, gelecekte uydu görüntülerini kullanarak geniş pamuk üretim alanlarında azot gereksinimlerini saptayarak azotlu gübre uygulama tavsiyelerinde bulunmak amacı ile yapılmıştır.

Yöntem ve Bulgular: Mardin ekolojik koşullarında, tesadüf parselleri deneme deseninde 3 tekerrürlü olarak 6 farklı lokasyonda yürütülmüştür. Çalışmada, PlanetScope uydusunun 4 (Blue, Green, Red ve NIR) bandı ve RapidEye uydusunun 5 (Blue, Green, Red, NIR ve RedEdge) bandı kullanılmıştır. İncelenen yaprak azot içeriği ile uydu görüntüleri arasındaki ikili ilişkilerin saptanması yapılarak, regresyon (yaprak azot içeriğiyansıma) ve ters regresyon (yansıma-yaprak azot içeriği) analizleri yapılmıştır. Yaprak azot içeriği ile RE_Blue ( $r=-$ $\left.0.58^{* *}\right)$, RE_Green $\left(r=-0.46^{* *}\right)$ ve RE_Red $\left(r=-0.67^{* *}\right)$, PS_Blue $\left(r=-0.54^{* *}\right)$, PS_Green $\left(r=-0.43^{* *}\right)$ ve PS_Red $\left(r=-0.42^{* *}\right)$ yansıma verileri arasında önemli korelasyon saptanmıştır.

Genel Yorum: Yaprak azot içeriğinin tahmin edilmesinde incelenen tüm uydu bantları arasından RE_Blue, RE_Green, RE_Red, PS_Blue, PS_Green, PS_Red uydu bantlarının kullanılması tavsiye edilmektedir.

Çalışmanın Önemi ve Etkisi: Bu çalışma, büyük pamuk 
üretim alanlarında azotlu gübre kullanım ihtiyacının varlığını tespit etmek yönünden büyük önem taşımaktadır. Özellikle GAP bölgesinde artan pamuk ekim alanları ve pamuk üretiminde azotlu gübreleme dikkate alındığında çalışma yaygın etki ve büyük alanlarda hızlı sonuç elde etme yönünden önemlidir.

Anahtar Kelimeler: Pamuk, azot, uydu görüntüleri, uzaktan algılama, RapidEye, PlanetScope.

\section{TEŞEKKÜR}

Bu çalışma, Dicle Üniversitesi Bilimsel Araştırma Projeleri Koordinasyon Birimi tarafından Ziraat.18.022 no'lu proje ile mali olarak desteklemiş olup, bu destekten dolayı Dicle Üniversitesi'ne teşekkür ederiz.

\section{ÇIKAR ÇATIŞMA BEYANI}

Yazar(lar) çalışma konusunda çıkar çatışmasının olmadığını beyan eder.

\section{ARAŞTIRMACILARIN KATKI ORANI BEYANI}

Yazarlar çalışmaya eşit oranda katkı sağlamış olduklarını beyan eder.

\section{KAYNAKLAR}

Anonim

http://www.nik.com.tr/content sistem_uydu.asp?id =67,http://www.nik.com.tr/content_sistem_uydu_g oruntuleri.asp. Erişim tarih: 10.08.2018.

Anonymous (1990) Approved methods of the American Association of Cereal Chemists. 8th ed. St. Paul: AACC.

Aytaç S, Başbağ S, Arslanoğlu F, Ekinci R, Ayan AK (2020) Lif bitkileri üretiminde mevcut durum ve gelecek. Türkiye Ziraat Mühendisliği IX. Teknik Kongresi, Bildiriler Kitabı-1, 13-17 Ocak, Ankara, Türkiye. pp:463-491.

Bagheri N, Ahmadi H, Alavipanah SK, Omid M (2013) Multispectral remote sensing for site-specific nitrogen fertilizer management. Pesq. agropec. bras. 48(10):1394-1401, DOI: 10.1590/S0100$204 \times 2013001000011$.

Ballester C, Hornbuckle J, Brinkhoff J, Smith J, Quayle W (2017) Assessment of In-Season Cotton Nitrogen Status and Lint Yield Prediction from Unmanned Aerial System Imagery. Remote Sens. 9(11):1149; doi:10.3390/rs9111149.

Başbağ S, Ekinci R, Akıncı C, Akın S, Tonçer Ö (2011) Diyarbakır ve Şanlıurfa illerinde Pamuk Sektörü Envanterinin Hazırlanması Projesi Sonuç Raporu. Karacadağ Kalkınma Ajansı, Diyarbakır.
Bibi Z, Khan N, Mussarat M, Khan MJ, Ahmad R, Khan IU, Shahen S (2011) Response of Gossypium hirsutum L. genotypes to various nitrogen levels. Pak. J. Bot., 43(5): 2403-2409.

Çabuk $A$, Uyguçgil $H$, Küpçü $S$, İnceoğlu $M$, Bektöre $E$, Çabuk SN, Çömert R, Işık Ö, Ersoy M (2019) Coğrafi Bilgi Sistemleri. Anadolu Üniversitesi, Yayın No: 3161, Eskişehir.5s.

Cao Q, Miao Y, Wang H, Huang S, Cheng S, Khosla R, Jiang $R$ (2013) Non-destructive estimation of rice plant nitrogen status with crop circle multispectral active canopy sensor. Field Crops Research 154 (2013) 133144.

Carter GA, Knapp AK (2001) Leaf optical properties in higher plants: linking spectral characteristics to stress and chlorophyll concentration. American Journal of Botany 88(4): 677-684.

Cassman KG, Doberman A, Walters DT (2002) Agroecosystems, nitrogen-use efficiency and nitrogen management. Ambio 31: 132-140

Chartuni E, Carvalho FA, Marçal D, Ruz E (2007) Precision agriculture: New tools to improve technology management in agricultural enterprises. Comunica. First edition, Second stage, January-April 2007.

Chen $\mathrm{P}$, Haboudane $\mathrm{D}$, Tremblay N, Wang J, Vigneault $\mathrm{P}$, Li B (2010) New spectral indicator assessing the efficiency of crop nitrogen treatment in corn and wheat. Remote Sensing of Environment 114 19871997.

Chen P, Wang J, Huang W, Tremblay N, Ou Y, Zhang Q (2013) Critical nitrogen curve and remote detection of nitrogen nutrition index for corn in the North Western Plain of Shandong Province, China. IEEE Journal of Selected Topics in Applied Earth Observations and Remote Sensing, 6(2):682-689; DOI: 10.1109/JSTARS.2012.2236302.

Clevers JGPW, Kooistra L (2012) Using hyperspectral remote sensing data for retrieving canopy chlorophyll and nitrogen content. IEEE Journal of Selected Topics in Applied Earth Observations and Remote Sensing, 5(2):574-583.

Delloyea C, Weissb M, Defourny P (2018). Retrieval of the canopy chlorophyll content from Sentinel-2 spectral bands to estimate nitrogen uptake in intensive winter wheat cropping systems. Remote Sensing of Environment 216: 245-261 https://doi.org/10.1016/j.rse.2018.06.037.

Eitel JUH, Magney TS, Vierling LA, Brown TT, Huggins DR (2014) LiDAR based biomass and crop nitrogen estimates for rapid, non-destructive assessment of wheat nitrogen status. Field Crops Research 159: 2132, https://doi.org/10.1016/j.fcr.2014.01.008. 
Erdle K, Mistele B, Schmidhalter U (2011) Comparison of active and passive spectral sensors in discriminating biomass parameters and nitrogen status in wheat cultivars. Field Crops Research 124: 74-84, https://doi.org/10.1016/j.fcr.2011.06.007.

Eroğlu E (2008) Bazı tarım ürünlerinin bitki besin element noksanlıkları ile elektromanyetik enerji yansıtma özellikleri arasındaki ilişkiler. Yüksek Lisans Tezi, Ege Üniversitesi Fen Bilimleri Enstitüsü Toprak ABD. Bornova/izmir. V-VIs.

Esetlili MT, Özen F, Kandemir BN, Kurucu Y, Bolca M (2015) Uzaktan Algılama Tekniği ile Pamuk Tarla Verimi Tahmin Doğruluğunun Arttırılmasında Kırmızı Kenar (Rededge) Band Kullanımının Katkısı. Ege Üniv. Ziraat Fak. Derg. 52 (2):161-168.

Filella I, Serrano L, Serra J, Peñuelas J (1995) Evaluating wheat nitrogen status with canopy reflectance indices and discriminant analysis. Crop Science: 35 : 1400-1405.

Fitzgerald G, Rodriguez D, O'Leary G (2010) Measuring and predicting canopy nitrogen nutrition in wheat using a spectral index-the canopy chlorophyll content index (CCCl). Field Crops Research 116: 318324.

Fridgen JL, Varco JJ (2004) Dependency of cotton leaf nitrogen, chlorophyll, and reflectance on nitrogen and potassium availability. Agronomy Journal, 96(1): 63-69.

Hakoomat A, Raheel AH (2011) Growth, Yield and Yield Components of American Cotton (Gossypium hirsutum L.) As affected by cultivars and nitrogen fertilizer. International Journal of Scientific \& Engineering Research, 2: 1-12.

Hernández-Cruz $A E$, Sánchez $E$, Preciado-Rangel $P$, García-Bañuelos ML, Palomo-Gil A, Espinoza-Banda A (2015) Actividad de la Nitrato Reductasa, Biomasa, Rendimiento y Calidad en Algodón en Respuesta a la Fertilización Nitrogenada. Revista Internacional De Botanica Experimental, 84: 454-460.

Huang S, Miao Y, Yuan F, Gnyp ML, Yao Y, Cao Q, Wang H, Lenz-Wiedemann VIS, Bareth G (2017) Potential of RapidEye and WorldView-2 satellite data for improving rice nitrogen status monitoring at different growth stages. Remote Sensing. 9(3): 227; 1-23; doi:10.3390/rs9030227.

Huang S, Miao Y, Zhao G, Yuan F, Ma X, Tan C, Yu W, Gnyp ML, Lenz-Wiedemann VIS, Rascher U, Bareth G (2015) Satellite remote sensing-based in-season diagnosis of rice nitrogen status in Northeast China. Remote Sensing. 7(8): 10646-10667; doi:10.3390/rs70810646.
Kaçar B (2009) Toprak analizleri, Nobel Akademik Yayıncılık Eğitim Danışmanlık Tic. Ltd. Şti.

Kaçar B, Katkat A (2011) Bitki Besleme, Nobel Akademik Yayıncılık Eğitim Danışmanlık Tic. Ltd. Şti.

Keskin M, Şekerli YE, Say SM, Arslan A (2018) Hassas Tarim Teknolojileri ile Sağlanabilecek Faydalar. Tarım Türk Dergisi, 30: 14-17.

Klema K, Záhorab J, Zemeka F, Trundaa P, Tůmab I, Novotnáa K, Hodaňováa $P$, Rapantováa $B$, Hanuša J, Vavř́kováb J, Holub P (2018) Interactive effects of water deficit and nitrogen nutrition on winter wheat. Remote sensing methods for their detection. Agricultural Water Management, 210: 171-184.

Li F, Miao Y, Hennig SD, Gnyp ML, Chen X, Jia L, Bareth G (2010) Evaluating hyperspectral vegetation indices for estimating nitrogen concentration of winter wheat at different growth stages. Precision Agriculture, 11:335-357.

Magney TS, Eitel JUH, Vierling LA (2016) Mapping wheat nitrogen uptake from RapidEye vegetation indices. Precision Agriculture, 18:429-451, DOI 10.1007/s11119-016-9463-8.

Mullen RW, Freeman KW, Raun WR, Johnson GV, Stone ML Solie JB (2003) Identifying an in-season response index and the potential to increase wheat yield with nitrogen. Agronomy Journal, 95: 347-351.

Mutanga O, Skidmore AK, Prins HHT (2004) Predicting in situ pasture quality in the Kruger National Park, South Africa using continuum-removed absorption features. Remote Sensing of Environment, 89(3):393408.

Patane P, Vibhute A (2014) Chlorophyll and nitrogen estimation techniques: A Review. International Journal of Engineering Research and Reviews, 2:3341.

Raun WR, Solie JB, Johnson GV, Stone ML, Mullen RW, Freeman KW, Thomason WE, Lukina EV (2002) Improving nitrogen use efficiency in cereal grain production with optical sensing and variable rate application. Agron. Journal. 94: 815-820.

Read JJ, Tarpleyb L, McKiniona JM Reddy KR (2002) Narrow-Waveband reflectance ratios for remote estimation of nitrogen status in cotton. Journal of Environmental Quality, 31: 1442-1452 doi:10.2134/jeq2002.1442.

Rochester IJ (2007) Nutrient Uptake and Export from an Australian Cotton Field. Nutrient Cycling in Agroecosystems, 77: 213-223. 
Schönert M, Zillmann E, Weichelt $H$, Eitel JUH, Magney TS, Lilienthalc $H$, Siegmannd B, Jarmer T (2015) The tasselled cap transformation for RapidEye data and the estimation of vital and senescent crop parameters. The International Archives of the Photogrammetry, Remote Sensing and Spatial Information Sciences, Volume XL-7/W3, 36th International Symposium on Remote Sensing of Environment, 11-15 May 2015, Berlin, Germany.

Seilsepour M, Rashidi M (2011) Effect of Different Application Rates of Nitrogen on Yield and Quality of Cotton (Gossypium hirsutum L.). American-Eurasian J. Agric. \& Environ. Sci., 10 (3): 366-370.

Spitkó T, Nagy Z, Zsubori ZT, Szőke C, Berzy T, Pintér J, Marton CL (2016) Connection between normalized difference vegetation index and yield in maize. Plant Soil Environ. 62: 293-298 DOI: 10.17221/676/2015PSE.

Sunar F, Özkan Ç, Osmanoğlu B (2018) Uzaktan Algılama. Anadolu Üniversitesi, Yayın No: 2320, Eskişehir. 3s.

Sutton MA, Howard CM, Erisman JW, Billen G, Bleeker A, Grennfelt P, Van Grinsven H, Grizzetti B (2011) The European Nitrogen Assessment: Sources, effects and policy perspectives. Cambridge, Cambridge University Press.

Türker U, Çullu MA, Mutlu N, Demir H, Bozgeyik F, Teke M (2015) GAP Bölgesinde Hassas Tarım ve Sürdürülebilir Uygulamaların Yaygınlaştırılması Projesi (Hassas Projesi). Tarım Makinaları Bilimi Dergisi, 11(4): 331-337.

USDA (2019) Cotton: World Markets and Trade, World Production, Markets, and Trade Reports, https://www.fas.usda.gov/data-analysis/scheduledreports-2019, Erişim Tarihi: 05.11.2019.
Vigneau N, Ecarnot M, Rabatel G, Roumet P (2011) Potential of field hyperspectral imaging as a nondestructive method to assess leaf nitrogen content in wheat. Field Crops Research, 122: 25-31.

Wang F, Wang K, Li S, Gao S, Xiao C, Chen B, Chen J, Lü Y, Diao W (2011) Estimation of canopy leaf nitrogen status using imaging spectrometer and digital camera in cotton. Acta Agronomica Sinica 37(6): 1039-1048 DOI: 10.3724/Sp.J.1006.2011.01039.

Wright DL, Rasmussen VP, Ramsey RD (2005) Comparing the use of remote sensing with traditional techniques to detect nitrogen stress in wheat. Geocarto International, 20(1):63-68; $\quad$ DOI: 10.1080/10106040508542337.

Yousefi MR, Razdari. AM (2014) Application of GIS and GPS in Precision Agriculture (A Review). International journal of Advanced Biological and Biomedical Research 2: 473-476.

Zhao D, Reddy KR, Kakani VG, Read JJ, Koti S (2005) Selection of optimum reflectance ratios for estimating leaf nitrogen and chlorophyll concentrations of field-grown cotton. Agronomy Journal, 97(1): 89-98; DOI: 10.2134/agronj2005.0089.

Zhao W, Wang Y, Zhou Z, Meng Y, Chen B, Oosterhuis DM (2012) Effect of nitrogen rates and flowering dates on fiber quality of cotton (Gossypium hirsutum L.) American Journal of Experimental Agriculture, 2: 133159. 